\title{
Micronutrientes em cultivares de gérbera de vaso ${ }^{(1)}$
}

\author{
FERNANDA LUDWIG ${ }^{(2,3)}$; DIRCEU MAXIMINO FERNANDES ${ }^{(2,4)}$; \\ POLIANA ROCHA D'ALMEIDA MOTA ${ }^{(2)}$; ROBERTO LYRA VILLAS BÔAS ${ }^{(2,4)}$
}

\begin{abstract}
RESUMO
O presente trabalho foi conduzido com o objetivo de avaliar o teor e o acúmulo de micronutrientes em quatro cultivares de gérbera fertirrigadas com duas soluções nutritivas. O experimento foi conduzido em casa de vegetação de maio a julho de 2006 no DRN/Ciência do Solo na FCA, Unesp, município de Botucatu/SP, Brasil. O delineamento experimental utilizado foi o de blocos casualizados, constituído de fatorial 4x2, sendo quatro cultivares de gérbera (Cherry, Golden Yellow, Salmon Rose e Orange) e duas concentrações de solução nutritiva (S1- 50\% e S2- 100\%). Ao final dos períodos vegetativo (41 DAA) e reprodutivo (62 DAA), foram quantificados o teor e o acúmulo dos micronutrientes no tecido vegetal da parte aérea. A cultivar Orange acumulou menor quantidade de micronutrientes $(59 \mathrm{mg} \mathrm{kg}-1 \mathrm{~B}, 5 \mathrm{mg} \mathrm{kg}-1 \mathrm{Cu}, 180 \mathrm{mg} \mathrm{kg}-1 \mathrm{Fe}, 46$ mg kg-1 Mn, ao final do ciclo) em relação às demais cultivares. $\mathrm{O}$ fornecimento da solução nutritiva mais concentrada se refletiu em maior teor dos micronutrientes no tecido. O maior acúmulo foi registrado no período reprodutivo, apresentando a seguinte ordem de absorção: $\mathrm{Fe}>\mathrm{Mn}>\mathrm{B}>\mathrm{Zn}>\mathrm{Cu}(237,72,71,30$ e $6 \mu \mathrm{g}$ planta-1).

Palavras-chave: Gerbera jamesonii, nutrição de plantas, fertirrigação.
\end{abstract}

\section{ABSTRACT \\ Micronutrients in potted gerbera cultivars}

\begin{abstract}
The present work aimed at evaluating the contents and accumulation in four different gerbera cultivars subjected to fertigation with two nutritive solutions. The experiment was carried out in a greenhouse, from May to July 2006, at DNR, Soil Science Sector, Agronomical Sciences College, UNESP, Botucatu, São Paulo State. The experiment was installed in randomized blocks and constituted of a $4 \times 2$ factorial scheme, being four gerbera cultivars (Cherry, Golden Yellow, Salmon Rose and Orange) and two concentrations of nutritive solution ( $\mathrm{S} 1-50 \%$ and $\mathrm{S} 2-100 \%)$, corresponding to the electrical conductivity of 0,92 and 1,76 dS m-1, during the vegetative period and 1,07 and 2,04 dS m-1, during the reproductive one. By the end of the vegetative (41 DAA) and reproductive (62 DAA) periods, were quantified the contents and accumulation of the micronutrients in vegetal tissue. The nutrients demands had been differentiated between the cultivars, smaller to Orange (59 mg kg-1 B, $5 \mathrm{mg} \mathrm{kg}-1 \mathrm{Cu}, 180 \mathrm{mg} \mathrm{kg}-1 \mathrm{Fe}, 46 \mathrm{mg} \mathrm{kg}-1 \mathrm{Mn}$, at the end of cycle). The supply of nutrient solution more concentrated reflected in a higher content of micronutrient in the tissue. The greatest accumulations had been registered at the reprodutive period, presentig the following order of absortion $\mathrm{Fe}>\mathrm{Mn}>\mathrm{B}>\mathrm{Zn}>\mathrm{Cu}(237,72,71,30$ e $6 \mu \mathrm{g}$ plant-1).
\end{abstract}

Keywords: Gerbera jamesonii, plant nutrition, fertigation.

\section{INTRODUÇÃO}

A gérbera (Gerbera jamesonii L.), pertencente à família Asteraceae, tem sua origem no sul da África e Ásia. Possui inúmeros híbridos de diversas combinações de cores e formas de suas inflorescências, o que a torna muito interessante ao mercado consumidor (RADICE e MARCONI, 1998). De acordo com LUDWIG et al. (2011), é uma das espécies floríferas que vêm se destacando no mercado de flores de plantas ornamentais, demandando ainda por pesquisas que objetivem a melhoria da quantidade e da qualidade produtiva.

A característica mais importante para que uma planta florífera cumpra sua função ornamental é seu aspecto saudável, atestando estar bem nutrida e hidratada (KÄMPF,
2000). Essa qualidade está associada ao adequado suprimento de nutrientes, e o baixo desempenho deles pode ser atribuído a desbalanços nutricionais (WESENBERG e BECK, 1964). Especificamente para gérbera de vaso, a qualidade relaciona-se com o conjunto equilibrado entre a parte vegetativa e a reprodutiva (LUDWIG et al., 2010).

Micronutrientes são nutrientes essenciais ao desenvolvimento da planta, exigidos em menores quantidades em relação aos macronutrientes (MALAVOLTA et al., 1997). Durante muito tempo, as adubações para as plantas ornamentais não eram supridas com os micronutrientes pelo desconhecimento de sua importância.

Estudos relacionados aos micronutrientes para gérbera envolvem principalmente a sintomatologia de clorose

\footnotetext{
(1) Recebido em 02/03/2010 e aceito para publicação em 13/11/2012.

(2) Departamento de Recursos Naturais / Ciência do Solo, Faculdade de Ciências Agronômicas (Unesp). Fazenda Experimental Lageado, Caixa Postal 237, 18610-307 Botucatu (SP).

(3) Autor para correspondência: ludwig.fernanda@yahoo.com.br

(4) Bolsista CNPq.
} 
à qual a cultura é sensível, especialmente em solos com elevado $\mathrm{pH}$, responsável pela insuficiente absorção de ferro e manganês (SONNEVELD e VOOGT, 1997; CABALERO et al., 2007).

Desordens estruturais em regiões de crescimento de plantas de gérbera têm sido relacionadas à deficiência de boro, micronutriente envolvido na função estrutural, especialmente na parede celular (KRUG, 2007). Esse autor observou que plantas que não receberam boro apresentaram sintomas de clorose, folhas mais espessas, onduladas e irregulares, em formato de concha. A concentração na folha menor que $1,70 \mathrm{mg} \mathrm{kg}^{-1}$ apresentou sintomas de deficiência, enquanto a concentração de $37,4 \mathrm{mg} \mathrm{kg}^{-1}$ não apresentou sintomatologia.

Poucos estudos foram realizados para o conhecimento da demanda nutricional de cultivares de gérbera de vaso, principalmente em relação aos micronutrientes. Desse modo, a presente pesquisa foi desenvolvida com o objetivo de avaliar o teor e o acúmulo de micronutrientes em cultivares de gérbera de vaso, fertirrigadas com duas soluções nutritivas.

\section{MATERIAL E MÉTODOS}

$\mathrm{O}$ experimento foi conduzido no período de maio a julho de 2006, em casa de vegetação do Departamento de Recursos Naturais (DRN) - Área de Ciência do Solo, FCA - Unesp, no município de Botucatu (22 $51^{\prime}$ 'S e $48^{\circ} 26^{\prime} \mathrm{W}$ ), estado de São Paulo, Brasil.

A casa de vegetação apresenta estrutura de teto em arco, com laterais de tela branca, pavimentada com concreto e 2,6 $\mathrm{m}$ de pé direito. $\mathrm{O}$ ambiente era mantido com intensidade luminosa inferior a 50.000 lux, com o uso de malha termorrefletora removível (Aluminet ${ }^{\mathbb{}}$ ). A temperatura média no interior do ambiente protegido foi de $20,5^{\circ} \mathrm{C}$ e a umidade relativa média do ar, de $69 \%$.

$\mathrm{O}$ delineamento experimental adotado foi em blocos casualizados, empregando o esquema fatorial $4 \times 2 \quad(4$ cultivares e 2 soluções nutritivas), em 5 repetições. As cultivares utilizadas eram provenientes do grupo Festival, da empresa Sakata ${ }^{\circledR}$, sendo Cherry e Golden Yellow, pertencentes à série "Dark Eyes" (centro escuro), e Salmon Rose e Orange, pertencentes à série "Light Eyes" (centro claro).

As soluções nutritivas constaram de uma referência padrão para gérbera de vaso, $100 \%\left(\mathrm{~S}_{2}\right)$, utilizada por empresa produtora de gérbera, e uma diluição em $50 \%$ da mesma solução $\left(\mathrm{S}_{1}\right)$. A composição da $\mathrm{S}_{2} \mathrm{em} \mathrm{mg} \mathrm{dm}^{-3}$ foi $142,0 \mathrm{~N}^{-\mathrm{NO}_{3}} ;$; 101,5 N-NH${ }_{4}^{+} ; 105,0 \mathrm{~K} ; 25,2 \mathrm{P} ; 51,3 \mathrm{Ca}$; $6,3 \mathrm{Mg} ; 28,0 \mathrm{~S} ; 0,2 \mathrm{~B} ; 0,3 \mathrm{Cu} ; 3,9 \mathrm{Fe} ; 1,4 \mathrm{Mn} ; 0,1 \mathrm{Mo}$ e $0,3 \mathrm{Zn}$, no período vegetativo. Estas composições foram reformuladas no período reprodutivo, após os 41 dias após a aclimatação (DAA), devido à mudança na demanda da cultura, tendo a seguinte composição $\mathrm{em} \mathrm{mg} \mathrm{dm} \mathrm{m}^{-3}: 110,3$ $\mathrm{N}-\mathrm{NO}_{3}^{-} ; 66,8 \mathrm{~N}^{-\mathrm{NH}_{4}}{ }_{4} ; 285,0 \mathrm{~K} ; 56,6 \mathrm{P} ; 26,3 \mathrm{Ca} ; 17,18 \mathrm{Mg}$; 76 S; 0,4 B; 0,4 Cu; 4,4 Fe; 1,7 Mn; 0,1 Mo e 0,5 Zn. Para a $\mathrm{S}_{1}$, a quantidade dos nutrientes foi reduzida pela metade, em ambos os períodos.

As condutividades elétricas (CE) no período vegetativo correspondentes às $\mathrm{S}_{1}$ e $\mathrm{S}_{2}$ foram de 0,92 e $1,76 \mathrm{dS} \mathrm{m}^{-1}$, respectivamente. No período reprodutivo, passaram para
1,07 e $2,04 \mathrm{dS} \mathrm{m}^{-1}$. O pH das soluções nutritivas foi ajustado para 5,0 com adição de ácido fosfórico (52\% $\mathrm{P}_{2} \mathrm{O}_{5}$ ), em ambos os períodos. As soluções preparadas foram estocadas em recipientes com capacidade de 90 litros.

Para a instalação do experimento, foram utilizadas mudas de gérbera para cultivo em vaso, com quatro folhas definitivas e raiz com torrão. Estas mudas foram transplantadas individualmente na posição central de vasos com volume de 1,3 litros (12,2 cm de altura, $14,8 \mathrm{~cm}$ de base superior e $9,8 \mathrm{~cm}$ de base inferior), preenchidos com substrato composto de $70 \%$ de casca de pinus fina e $30 \%$ de terra de subsolo. O substrato apresentou densidade úmida de $732 \mathrm{~kg} \mathrm{~m}^{-3}$ e densidade seca de $691 \mathrm{~kg} \mathrm{~m}^{-3}$, espaço de aeração de $6,47 \%$, água facilmente disponível de 18,7\%, distribuição do tamanho de partículas de $6,79 \%$ (partículas $>4 \mathrm{~mm}$ ), $14,16 \%$ (4 a $2 \mathrm{~mm}$ ), 13,29\% (2 a $1 \mathrm{~mm}$ ), $21,71 \%$ (1 a $0,5 \mathrm{~mm}), 25,01 \%(0,5$ a $0,25 \mathrm{~mm})$ e $19,04 \%(<0,25$ $\mathrm{mm}), \mathrm{CE}_{1: 5}$ de $0,56 \mathrm{dS} \mathrm{m}^{-1}$ e $\mathrm{pH}_{1: 5}$ de 6,62 .

As plantas foram aclimatadas durante 30 dias em empresa especializada na produção de gérbera, mantidas sob malha termorrefletora, visando a manter a intensidade luminosa próxima a 25.000 Lux. Após a aclimatação, os vasos foram levados à casa de vegetação do DRN e espaçados de $0,30 \mathrm{em} 0,30 \mathrm{~m}$, em tijolos dispostos no seu piso, totalizando uma área útil de $21,6 \mathrm{~m}^{2}$, com $14,4 \mathrm{~m}$ de comprimento e $1,5 \mathrm{~m}$ de largura.

Os nutrientes foram fornecidos às plantas por meio da fertirrigação, aplicada manualmente, uma vez ao dia, visando a elevar a umidade do substrato contido no vaso ao valor correspondente à condição de máxima retenção de água. A quantidade média de solução nutritiva fornecida às cultivares Golden Yellow e Orange foi de $100 \mathrm{~mL}$ vaso $^{-1}$ dia $^{-1}$ nos períodos vegetativo e reprodutivo. Para as cultivares Cherry e Salmon Rose, foi de $100 \mathrm{~mL}$ vaso $^{-1}$ dia $^{-1}$ no período vegetativo e $150 \mathrm{~mL}$ vaso $^{-1}$ dia $^{-1}$ no período reprodutivo. Assim, em função das diferentes necessidades hídricas, as duas primeiras cultivares receberam ao longo do ciclo $5,2 \mathrm{~L}$ de solução por vaso e as demais, $5,9 \mathrm{~L}$.

A determinação do teor e do acúmulo dos micronutrientes boro $(\mathrm{B})$, cobre $(\mathrm{Cu})$, ferro $(\mathrm{Fe})$, manganês $(\mathrm{Mn})$ e zinco $(\mathrm{Zn})$ foi feita ao final dos períodos vegetativo e reprodutivo (41 e 62 DAA, respectivamente). As plantas foram cortadas rente ao substrato, lavadas, acondicionadas em sacos de papel "Kraft" e mantidas em estufa de ventilação forçada a $65^{\circ} \mathrm{C}$ até peso constante. Elas foram pesadas em balança digital a fim de obter a fitomassa seca, em grama (g), e moídas em moinho do tipo "Willey". A análise química do tecido das plantas para a determinação dos teores dos micronutrientes seguiu a metodologia recomendada por MALAVOLTA et al. (1997). O acúmulo dos micronutrientes foi calculado pelo produto da fitomassa seca e os respectivos teores.

Os resultados foram submetidos à análise de variância pelo teste F. As médias obtidas em função das cultivares e das soluções foram comparadas pelo teste Tukey a 5\% de probabilidade, com o uso do programa estatístico Sisvar (FERREIRA, 2000). Procedeu-se ao desdobramento da interação entre cultivares e soluções nutritivas quando a análise da variância revelou efeito significativo. 


\section{RESULTADOS E DISCUSSÃO}

$\mathrm{O}$ teor e o acúmulo dos micronutrientes no tecido vegetal variaram em função das cultivares, exceto para o teor de manganês aos 41 DAA (Tabela 1) e acúmulo de cobre aos 41 DAA (Tabela 2). Em função das soluções nutritivas, somente não ocorreu efeito significativo para o teor de cobre aos 41 DAA e de zinco aos 62 DAA (Tabela 1) e acúmulo de cobre aos 41 e 62 DAA (Tabela 2). Interações entre cultivares e soluções nutritivas foram verificadas para o teor de zinco aos 62 DAA (Tabela 1) e acúmulo de boro aos 41 DAA (Tabela 2).

Os teores de boro foram superiores na cultivar Salmon Rose aos 41 DAA (70 mg kg-1) e 62 DAA (78 mg kg$\left.{ }^{1}\right)$, sem diferir estatisticamente de Cherry $\left(61 \mathrm{mg} \mathrm{kg}^{-1}\right) \mathrm{e}$ Orange (60 mg kg-1) aos 41 DAA e de Cherry $\left(74 \mathrm{mg} \mathrm{kg}^{-1}\right)$ e Golden Yellow (71 $\mathrm{mg} \mathrm{kg}^{-1}$ ) aos 62 DAA. Salmon Rose também apresentou maior acúmulo quando submetida à solução mais concentrada $\left(\mathrm{S}_{2}\right)$ no período vegetativo, com valor de $530 \mu \mathrm{g}_{\text {planta }}{ }^{-1}$ (Tabela 3 ) e em ambas as soluções no período reprodutivo, com valor de $990 \mu \mathrm{g}$ planta $^{-1}$, sem diferir de Cherry, com valor de $880 \mu$ g planta $^{-1}$ (Tabela 2).

Teores de boro entre 20 a $60 \mathrm{mg} \mathrm{kg}^{-1}$ são sugeridos como adequados por JONES Jr. et al. (1996) para a cultura da gérbera. As plantas conduzidas com a $\mathrm{S}_{2}$ responderam com o aumento no teor e no acúmulo deste nutriente (Tabelas 1, 2 e 3), situando-se acima da recomendação dos autores (81 e $93 \mathrm{mg} \mathrm{kg}^{-1}$, nos períodos vegetativo e reprodutivo, respectivamente). Em trabalho desenvolvido por MOTA (2007), foram obtidos teores médios de $63 \mathrm{mg} \mathrm{kg}^{-1}$ para a cultivar Cherry, $59 \mathrm{mg} \mathrm{kg}^{-1}$ para a cultivar Golden Yellow e $48 \mathrm{mg} \mathrm{kg}^{-1}$ para a cultivar Salmon Rose. Desse modo, considerando as mesmas cultivares e aquelas próprias para vaso, os valores obtidos são adequados e podem servir como referência.

Sintomas de toxidez por boro em plantas de gérbera de vaso somente foram observados por JEONG et al. (2009) em concentrações de 394,5 $\mathrm{mg} \mathrm{kg}^{-1}$, com amarelecimento das margens $\mathrm{e}$ progressiva clorose internerval, enquanto plantas com $48,4 \mathrm{~m} \mathrm{~kg}^{-1}$ apresentaram desenvolvimento normal Sintomas de deficiência deste micronutriente foram observadas por KRUG (2007) com teores inferiores a $1,7 \mathrm{mg} \mathrm{kg}^{-1}$.

De acordo com KRUG (2007), a absorção de boro está intimamente relacionada com a transpiração, e sua disponibilidade varia em função da umidade no solo ou substrato, decrescendo em condições de déficit hídrico. Plantas de diferentes espécies ou de diferentes genótipos dentro de uma mesma espécie podem ter diferentes permeabilidades de membrana, que seriam responsáveis pelas diferentes taxas de absorção (MARSCHNER, 1995), justificando as diferenças observadas na literatura.

Até os 41 DAA, um terço da quantidade de boro havia sido incorporado à planta, com valores de $288 \mathrm{mg} \mathrm{planta}^{-1}$, e nos 21 dias finais de ciclo, o acúmulo triplicou, com valores de $818 \mathrm{mg} \mathrm{planta}^{-1}$. A importância desse nutriente é destacada por GUPTA (2007) durante o estádio de formação de flores e sementes de plantas.

A cultivar Golden Yellow apresentou maiores teores de cobre no tecido vegetal, com $6 \mathrm{mg} \mathrm{kg}^{-1}$ aos 41 DAA e $7 \mathrm{mg}$ $\mathrm{kg}^{-1}$ aos 62 DAA, sem diferir estatisticamente de Salmon
Rose e Orange ( $\left.5 \mathrm{mg} \mathrm{kg}^{-1}\right)$ os 41 DAA e Salmon Rose aos 62 DAA ( $7 \mathrm{mg} \mathrm{kg}^{-1}$ ) (Tabela 1). Esse mesmo comportamento foi observado para o acúmulo aos 62 DAA (Tabela 2).

Os teores de cobre considerados adequados, obtidos em folhas novas completamente expandidas, divergem entre autores, situando-se entre 8 a $12 \mathrm{mg} \mathrm{kg}^{-1}$ para MERCURIO (2002) e de 6 a $50 \mathrm{mg} \mathrm{kg}^{-1}$ para JONES Jr et al. (1996). Com isso, é possível inferir que a necessidade depende da cultivar, pois mesmo nos valores abaixo do considerado adequado, as cultivares Cherry e Orange não apresentaram sintomas de deficiência. Essa sintomatologia é descrita por JEONG et al. (2009) pela presença de folhas jovens distorcidas e clorose internerval em folhas recentemente maduras, observadas na concentração de $1,8 \mathrm{mg} \mathrm{kg}^{-1}$. MOTA (2007) obteve $2 \mathrm{mg} \mathrm{kg}^{-1}$ para Salmon Rose e também não verificou sintomas visuais de carência. Considera-se também a possibilidade de ocorrência de competição entre o cobre e o manganês, já que somente o último aumentou consideravelmente dos 41 aos 62 DAA.

KOPSELL e KOPSELL (2007) comentam que o teor de cobre no tecido vegetal é dependente do $\mathrm{pH}$ do meio de cultivo, aumentando naqueles com valores inferiores a 7,0 . Portanto, além da demanda da cultivar, é importante determinar o $\mathrm{pH}$ do meio de cultivo.

Aos 41 DAA, independentemente da concentração da solução nutritiva aplicada, o teor de cobre foi semelhante, com $5 \mathrm{mg} \mathrm{kg}^{-1}$. Entretanto, aos $41 \mathrm{DAA}$, as plantas fertirrigadas com a solução menos concentrada $\left(\mathrm{S}_{1}\right)$ apresentaram maior absorção deste micronutriente (7 $\mathrm{mg} \mathrm{kg}{ }^{-1}$ ). Resultados semelhantes foram observados por BELLÉ (1998), no período reprodutivo, com decréscimo dos teores em função do aumento da concentração salina da solução.

De modo semelhante ao observado para o boro, a quantidade de cobre acumulada triplicou no terço final do ciclo da gérbera, quando aumentou de $20 \mu \mathrm{g}_{\text {planta }}{ }^{-1}$ (41 DAA) para $70 \mu$ p planta $^{-1}(62 \mathrm{DAA})$.

Diferenças no teor e no acúmulo de ferro foram encontradas entre as cultivares (Tabelas 1 e 2). Cherry apresentou maior teor (200 e $304 \mathrm{mg} \mathrm{kg}^{-1}$ ) e acúmulo (880 e $3540 \mu \mathrm{g}$ planta $\left.^{-1}\right)$ nos períodos vegetativo e reprodutivo. Segundo D'AGLIANO et al. (1994), cultivares de gérbera têm diferentes requerimentos de ferro.

$\mathrm{O}$ aumento da concentração de ferro na solução nutritiva mais concentrada $\left(\mathrm{S}_{2}\right)$ promoveu aumento desse nutriente no tecido vegetal (Tabela 2). Este efeito foi mais expressivo aos 62 DAA, verificando-se o dobro do teor quando comparado à $\mathrm{S}_{1}$. Não há consenso na literatura sobre os teores de $\mathrm{Fe}$ adequados para a cultura da gérbera, já que MERCURIO (2002) considera suficientes valores entre 450 a $500 \mathrm{mg} \mathrm{kg}^{-1}$, JONES Jr et al. (1996), entre 50 a $200 \mathrm{mg} \mathrm{kg}^{-1}$, e ANJANEYULUS (2008), entre 225 e 287 $\mathrm{mg} \mathrm{kg}{ }^{-1}$.

SAVVAS e GIZAS (2002) encontraram teores de ferro mínimos de $69 \mathrm{mg} \mathrm{kg}^{-1}$ para a cultivar Maya, sem registrar sintomas de deficiência. MOTA (2007) obteve valores de $77 \mathrm{mg} \mathrm{kg}^{-1}$ para a cultivar Cherry, $82 \mathrm{mg} \mathrm{kg}^{-1}$ para a cultivar Golden Yellow e $112 \mathrm{mg} \mathrm{kg}^{-1}$ para a cultivar Salmon Rose. Os resultados divergentes são atribuídos ao uso de diferentes cultivares, que podem apresentar demanda diferenciada. Além disso, 
o substrato é essencial para promover tais diferenças, principalmente em função do $\mathrm{pH}$ e da umidade. Em condições de elevado $\mathrm{pH}$, a solubilidade do $\mathrm{Fe}^{+3}$ a $\mathrm{Fe}^{+2}$ diminui, reduzindo sua disponibilidade (RÖMHELD e NIKOLIC, 2007). Já em condições anaeróbicas, pode ocorrer toxidez de ferro para as culturas pela redução do $\mathrm{Fe}^{+3}$ a Fe ${ }^{+2}$ (MALAVOLTA, 2006).

Sintomas iniciais de deficiência de ferro em plantas envasadas de gérbera, com clorose internerval em folhas recentemente maduras, foram observados por JEONG et al. (2009) quando a concentração foi de $40 \mathrm{mg} \mathrm{kg}^{-1}$, comparado com a testemunha, com $67 \mathrm{mg} \mathrm{kg}^{-1}$.

Conforme verificado para os demais micronutrientes, o acúmulo de ferro foi superior durante o período reprodutivo, atingindo 3,7 vezes o acumulado no vegetativo, passando de $730 \mu \mathrm{g}$ planta ${ }^{-1}$ aos 41 DAA para $2750 \mu \mathrm{g}_{\text {planta }}{ }^{-1}$ aos 62 DAA, em média.

O teor de manganês foi superior na cultivar Cherry, com $85 \mathrm{mg} \mathrm{kg}^{-1}$, sem diferir de Golden Yellow, com $78 \mathrm{mg} \mathrm{kg}^{-1}$, e de Salmon Rose, com $80 \mathrm{mg} \mathrm{kg}^{-1}$. Os maiores acúmulos foram registrados em Salmon Rose e Golden Yellow, nos dois períodos, sem diferir de Cherry aos 62 DAA (Tabela 2).

Plantas de gérbera fertirrigadas com a solução mais concentrada $\left(\mathrm{S}_{2}\right)$ apresentaram maior teor e acúmulo de manganês em seu tecido (Tabelas 1 e 2). Os valores referenciais obtidos na literatura são de 40 a $250 \mathrm{mg} \mathrm{kg} \mathrm{kg}^{-1}$ (JONES Jr. et al., 1996), 40 a $50 \mathrm{mg} \mathrm{kg}^{-1}$ (MERCURIO, 2002) e 88 a $126 \mathrm{mg} \mathrm{kg}^{-1}$ (ANJANEYULUS, 2008). O pH do solo ou substrato é o principal fator que afeta a absorção do manganês (HUMPHRIES et al., 2007), reduzindo-se com elevação do $\mathrm{pH}$, com consequente clorose (SONNEVELD e VOOGT, 1997).

De forma mais acentuada que o observado para os demais micronutrientes, o acúmulo de manganês no período reprodutivo $\left(850 \mu \mathrm{g} \mathrm{planta}^{-1}\right)$ foi 4,6 vezes superior em relação ao vegetativo $\left(183 \mu \mathrm{g}\right.$ planta $\left.^{-1}\right)$, mostrando a importância de uma maior suplementação deste nutriente no momento em que as estruturas reprodutivas são formadas.

Maior teor e acúmulo de zinco foram encontrados no tecido vegetal da cultivar Salmon Rose, com valores médios de $39 \mathrm{mg} \mathrm{kg}^{-1}$, nos dois períodos, e 203 e $501 \mu \mathrm{g}$ planta-1, nos períodos vegetativo e reprodutivo, respectivamente (Tabela 1). O efeito da interação entre cultivares e soluções nutritivas para o teor deste nutriente foi observado aos 62 DAA (Tabela 3). Quando as cultivares foram fertirrigadas com a $\mathrm{S}_{1}$, os maiores teores foram registrados para Golden (38 $\mathrm{mg} \mathrm{kg}^{-1}$ ) e Salmon Rose (35 $\mathrm{mg} \mathrm{kg}^{-1}$ ); quando fertirrigadas com a solução mais concentrada $\left(\mathrm{S}_{2}\right)$, o maior teor foi registrado para Salmon $\left(43 \mathrm{mg} \mathrm{kg}^{-1}\right)$. Diferença significativa entre as soluções somente ocorreu para a cultivar Salmon Rose, com menor teor desse micronutriente na solução menos concentrada $\left(\mathrm{S}_{1}\right)$.

Os teores de zinco são considerados elevados por MERCURIO (2002), que apresenta a faixa de 6 a 8 mg kg-1 como ideal. Contudo, estão próximos dos verificados por MOTA (2007) com valores de $22 \mathrm{mg} \mathrm{kg}^{-1}$ para Cherry e Golden Yellow e $33 \mathrm{mg} \mathrm{kg}^{-1}$ para Salmon Rose.

JEONG et al. (2009) descrevem a sintomatologia de deficiência de zinco pela presença de folhas mais espessas e menores, com redução significativa no peso seco da planta, observadas naquelas cujo teor foi de $6,5 \mathrm{mg} \mathrm{kg}^{-1}$, comparada com o controle com $11,7 \mathrm{mg} \mathrm{kg}^{-1}$.

Ao final do ciclo (62 DAA), verificou-se aumento de 2,6 vezes no acúmulo de zinco em relação ao período vegetativo (41 DAA). Esse acentuado acréscimo no período reprodutivo ocorreu para todos os micronutrientes, indicando que a maior demanda ocorre nesta época, que pode ser atendida com o manejo da fertirrigação. $\mathrm{O}$ resultado corrobora a afirmação de HAAG et al. (1981), os quais indicam que a absorção de nutrientes varia com a fase de desenvolvimento da cultura, intensificando-se no florescimento.

Há uma grande diferença no requerimento dos micronutrientes entre cultivares de gérbera, pois foram encontrados valores muito divergentes na literatura, no entanto sem que houvesse deficiência ou toxidez. Destacase também a importância na definição do órgão da planta a ser utilizado na análise nutricional, já que estes órgãos têm diferentes demandas nutricionais, gerando dificuldades na comparação e padronização de valores ideais.

\section{CONCLUSÃO}

A cultivar Orange acumulou menor quantidade de micronutrientes (59 mg kg $\mathrm{kg}^{-1}$, $5 \mathrm{mg} \mathrm{kg}^{-1} \mathrm{Cu}, 180 \mathrm{mg} \mathrm{kg}^{-1} \mathrm{Fe}, 46 \mathrm{mg} \mathrm{kg}^{-1} \mathrm{Mn}$, ao final do ciclo) em relação às demais cultivares.

O fornecimento da solução nutritiva mais concentrada se refletiu em maior teor dos micronutrientes no tecido.

O maior acúmulo foi registrado no período reprodutivo, apresentando a seguinte ordem de absorção: $\mathrm{Fe}>\mathrm{Mn}>\mathrm{B}>\mathrm{Zn}>\mathrm{Cu}\left(237,72,71,30\right.$ e $6 \mu \mathrm{g}$ planta $\left.^{-1}\right)$.

\section{REFERÊNCIAS}

ANJANEYULU, K. Diagnostic leaf nutrient norms and identification of yield limiting nutrients in gerbera grown under protected conditions using DRIS. Indian Journal of Horticulture, New Delhi, v.65, p.176-179, 2008.

BELLÉ, S. Sistemas de irrigação e concentrações de adubação complementar na produção de Gerbera jamesonii cv 1187 em vaso. 1998. 122f. Tese (Doutorado em Fitotecnia) - Porto Alegre, Universidade Federal do Rio Grande do Sul. 1998.

CABALLERO, R. et al. Iron chlorosis in gerber as related to properties of various types of compost used as growing media. Communications in Soil Science and Plant Analysis, Philadelphia, v.38, p.2357-2369, 2007.

D'AGLiAnO, G.; CARRAI, C.; BIGONGIARI, G. Preliminary evaluation of a hydroponic recirculating nutrient system for gerbera cultivation. Acta Horticulturae, Wageningen, v. 361, p. 414-422, 1994.

FERREIRA, D.F. Análises estatísticas por meio do Sisvar para Windows versão 4.0. In: 45a Reunião Anual da Região Brasileira da Sociedade internacional de Biometria. Anais... UFSCar, São Carlos, Brasil, 255-258. 2000 . 
GUPTA, U.C. Boron. In: BARKER, A.V.; PILBEAM, D.J. Handbook of plant nutrition. Boca Raton, Florida: Taylor Francis Publishing Group, 2007. p. 241-277.

HAAG, P.H. et al. Marcha de absorção de nutrientes pelo tomateiro (Licopersicum esculentum Mill) destinado ao processamento industrial. In: HAAG, H.P.; MINAMI, K. Nutrição mineral de hortaliças. Campinas: Fundação Cargill, 1981. p.447-474.

HUMPHRIES, J.M.; STANGOULIS, J.C.R.; GRAHAM, R.D. Manganese. In: BARKER, A.V.; PILBEAM, D.J. Handbook of plant nutrition. Boca Raton, Florida: Taylor Francis Publishing Group, 2007. p.351-374.

JEONG, K.Y. et al. Characterization of nutrient disorders of gerbera hybrid 'Festival Light Eye Pink'. Acta Horticulturae, Wageningen, v.843, p.177-182. 2009.

JONES JR., J. B.; WOLF, B.; MILLS, H. A. Plant analysis handbook. Athens: Micro-Macro Publishing, 1996. 213 p. KÄMPF, A. N. Produção comercial de plantas ornamentais. Guaíba: Agropecuária. 2000. 254p.

KOPSELL, D.E.; KOPSELL, D.A. Copper. In: BARKER, A.V.; PILBEAM, D.J. Handbook of plant nutrition. Boca Raton, Florida: Taylor Francis Publishing Group, 2007. p.293-328.

KRUG, B. A. Physiological and environmental factors affecting shoot tissue boron concentration of pansy (Viola $\times$ wittrockiana), petunia (Petunia $\times$ hybrida), and gerbera (Gerbera jamesonii) plugs. 2007. 129f. Tese (Doutorado em Fisiologia) - Raleigh, North Carolina State University. 2007.

LUDWIG, F. et al. Crescimento e produção de gérbera fertirrigada com solução nutritiva. Horticultura Brasileira, Brasilia, v.28, p.424-429, 2010.

LUDWIG, F. et al. Qualidade de cultivares de gérbera de vaso em função das características físicas e químicas dos substratos. Revista Brasileira de Horticultura Ornamental, Campinas, v.17, p.141-148, 2011.
MALAVOLTA, E.; VITTI, G.C.; OLIVEIRA, S.A. Avaliação do estado nutricional das plantas: princípios e aplicações. Piracicaba: Potafos. 1997. 319p.

MALAVOLTA, E. Manual de nutrição mineral de plantas. São Paulo. Ceres, 2006. 638 p.

MARCHNER, H. Mineral nutrition of higher plants. New York: Academic Press, 1995. 889 p.

MERCURIO, G. Gerbera cultivation in greenhouse. Netherlands: Schreurs, 2002. 206 p.

MOTA, P.R.D. Aplicação via fertirrigação de soluções com diferentes condutividades elétricas para produção de gérbera (Gerbera jamesonii L.) sob ambiente protegido. 2007. 149f. Tese (Doutorado em Agronomia/ Irrigação e Drenagem) - Botucatu, Faculdade de Ciências Agronômicas, UNESP. 2007.

RADICE, S.; MARCONI, P.L.; Clonación in vitro de diversos cultivares de Gerbera jamesonii a partir de capítulos florales. Revista de la Facultad de Agronomía, La Plata. v. 103, 1998.

RÖMHELD, V.; NIKOLIC, M. Iron. In: BARKER, A.V.; PILBEAM, D.J. Handbook of plant nutrition. Boca Raton, Florida: Taylor Francis Publishing Group, 2007. p.392-350.

SAVVAS, D.; GIZAS, G. Response of hydroponically grown gerbera to nutrient solution recycling and different cation ratios. Scientia Horticulturae, Amsterdam, v.96, p.267-280, 2002.

SONNEVELD, C.; VOOGT, W. Effects of $\mathrm{pH}$ and $\mathrm{Mn}$ application on yield and nutrient absorption with rockwool grown gerbera (refereed). Acta Horticulturae, Wageningen, v.450, p.139-147, 1997.

WESENBERG, B. G.; BECK, G. E. Influence of production environment and others factors the potted chrysantemum flowers (Chrysantemum morifolium Ramat). Proceedings American Society of the Horticultural Science, Maryland, v.85, p.584-590, 1964. 
Tabela 1. Teor de micronutrientes no tecido vegetal de cultivares de gérbera de vaso fertirrigadas com duas soluções nutritivas. Botucatu (SP), Brasil, 2006

Table 1. Vegetal tissue micronutrient contents of potted gerbera cultivars fertigated with two nutrient solutions. Botucatu (SP), Brazil, 2006

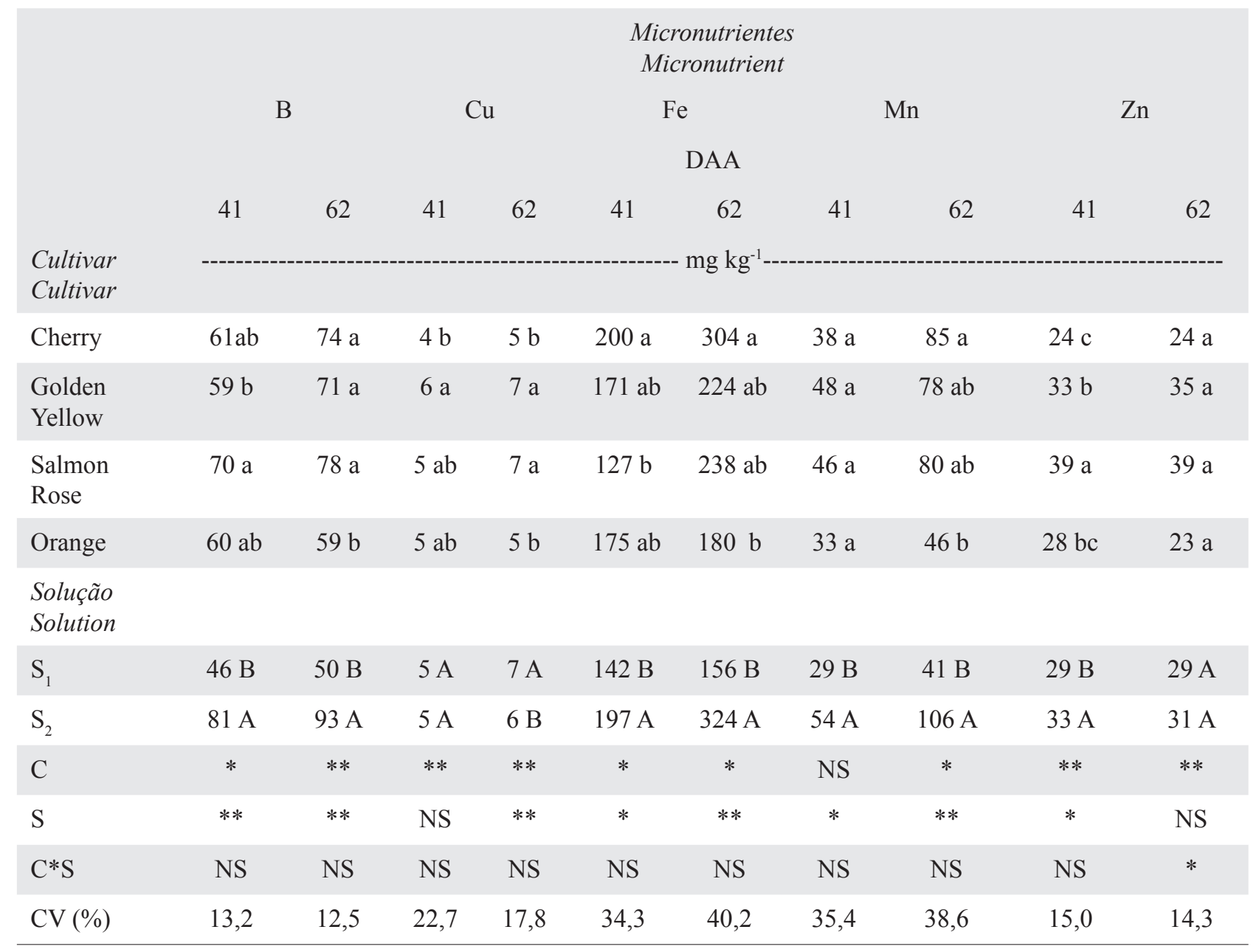

C: cultivar; S: solução nutritiva. DAA: dias após aclimatação. NS: não significativo ao nível de $5 \%$ *: significativo a $5 \%$ de probabilidade. **: significativo a 1\% de probabilidade. S1: CE de 0,92 e 1,07 dS m-1; S2: 1,76 e 2,04 dS m-1 (período vegetativo e reprodutivo respectivamente). Médias seguidas pela mesma letra minúscula na coluna para cultivar e maiúscula na coluna para solução, não diferem entre si pelo teste Tukey a $5 \%$.

C: cultivars; S: nutrient solutions. NS: not significant. DAA: days after acclimation. **significant at 1\%. *significant at 5\%. S1: EC 0,92 and 0,92 and 1,07 dS m-1; S2: 1,76 and 2,04 dS m-1 (vegetative and reproductive stages). Means followed by the same lowercase letters in the column for cultivar and uppercase letters in the column for solution did not differ by the Tukey's test at $5 \%$. 
Tabela 2. Acúmulo de micronutrientes no tecido vegetal de cultivares de gérbera de vaso fertirrigadas com duas soluções nutritivas. Botucatu (SP), Brasil, 2006

Table 2. Vegetal tissue micronutrient accumulation of potted gerbera cultivars fertigated with two nutrient solutions. Botucatu (SP), Brazil, 2006

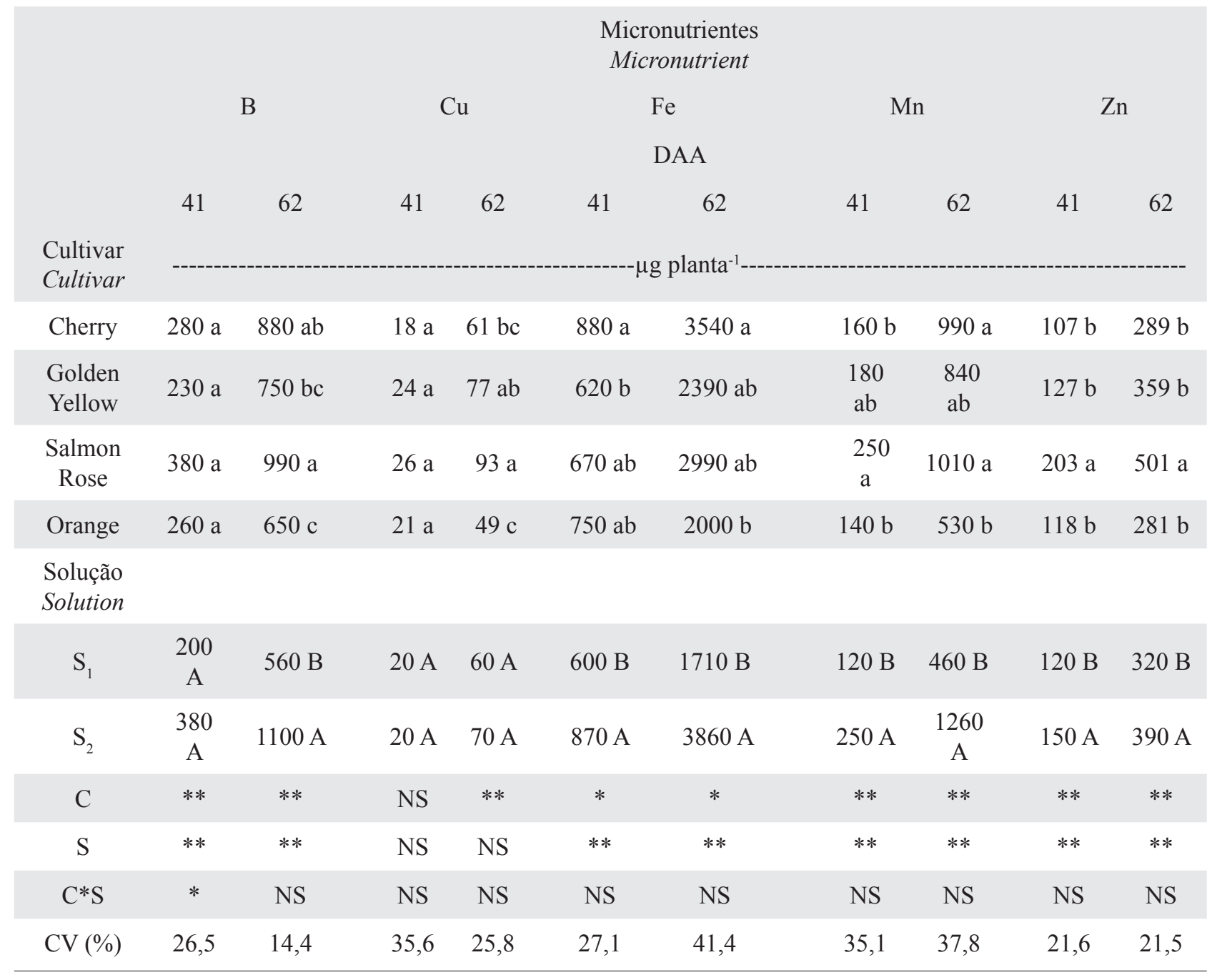

C: cultivar; S: solução nutritiva. NS: não significativo ao nível de 5\%. DAA: dias após aclimatação. *: significativo a 5\% de probabilidade. **: significativo a 1\% de probabilidade. S1: CE de 0,92 e 1,07 dS m-1; S2: 1,76 e 2,04 dS m-1 (período vegetativo e reprodutivo respectivamente). Médias seguidas pela mesma letra minúscula na coluna para cultivar e maiúscula na coluna para solução, não diferem entre si pelo teste Tukey a $5 \%$.

C: cultivars; S: nutrient solutions. NS: not significant. **significant at 1\%. *significant at 5\%. DAA: days after acclimation. S1: EC 0,92 and 0,92 and $1,07 \mathrm{dS}$ m-1; S2: 1,76 and 2,04 dS m-1 (vegetative and reproductive stages). Means followed by the same lowercase letters in the column for cultivar and uppercase letters in the column for solution did not differ by the Tukey's test at $5 \%$. 
Tabela 3. Acúmulo de B (41 DAA) e teor de Zn (62 DAA) no tecido vegetal de plantas de gérbera de vaso fertirrigadas com duas soluções nutritivas. Botucatu (SP), Brasil, 2006

Table 3. B accumulation (41 DAA) and Zn content (62 DAA) in vegetal tissue of potted gerbera cultivars fertigated with two nutrient solutions. Botucatu (SP), Brazil, 2006

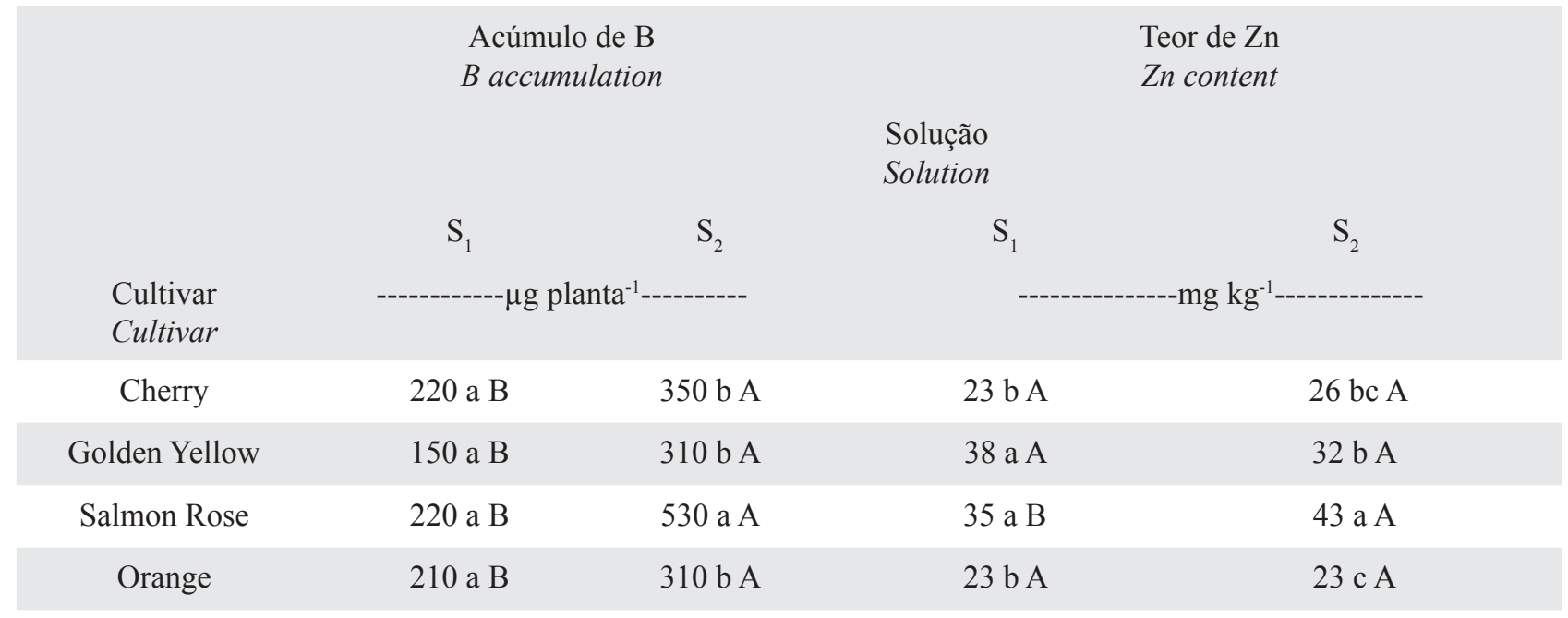

Valores seguidos pelas mesmas letras minúsculas na coluna e maiúsculas na linha, não diferem entre si pelo teste de Tukey a $5 \%$. CE de 0,92 e 1,07 dS m-1; S2: 1,76 e 2,04 dS m-1 (período vegetativo e reprodutivo respectivamente).

Means followed by the same lowercase letters in the column for cultivar and uppercase letters in the line for solution did not differ by the Tukey's test at 5\%. S1: EC 0,92 and 0,92 and 1,07 dS m-1; S2: 1,76 and 2,04 dS m-1 (vegetative and reproductive stages). 